\title{
The analysis for Beijing's service industry and its effects on regional development
}

\author{
Deng Xin ${ }^{1, *}$ \\ ${ }^{1}$ North China University of Technology, School of Economics and Management, No.5 Jinyuanzhuang \\ Road, ShiJingShan District, 100144 Beijing, P. R. China
}

\begin{abstract}
This paper calculates the influence and induction coefficient based on the input-output theory, in order to evaluate the current situation of Beijing's service industry and its effects on regional development. With online comparison, the author concludes that the service sector is getting more and more important on economic development, while the second industry is still the pillar of growth. The author also finds that the impact of service sector's influence coefficient on the growth rate of regional economy and the scope of industry is weaker than the induction coefficient. At last, this paper shows that the fundamental compelling power for Beijing's service development is from the demand side of market, and this gives the benchmark point for policy making in service sector.
\end{abstract}

Key words: total input coefficients, influence coefficient, induction coefficient, service industry, regional development

\section{Introduction}

Beijing which is a key economic area in China adjusts the economics structure actively, and promotes the transformation of economic development patterns positively. Review studies have shown that Beijing has the comparative advantage to undertake the international service transfer, and makes it fully use is the best way for Beijing to development the service sectors [1]. But compared with the Beijing performance in FDI using, the FDI using of Beijing service is just the beginning, so it has a considerable to grow [2]; the study based on the space structure shows that there are multicenter on the development of Beijing service sector [3]; although there exists difference on the spatial distribution of services and manufacturing, the positive relationship between the input of Beijing producer service and manufacturing efficiency was verified [4].The statistics based the time series data show services sector become to be one of the three major factors that affect economic growth [5],but structural flaws is pointed and the competitive advantage is gradually weakened [6].

The existing studies pay more attention on the situations and the characteristics of Beijing service sectors; make full positive analysis on the roles of services to economic development and the competitiveness. But the research on the relationship of economy and technology in different -specific services industry are not enough, this paper is guided by the theory of input and output, analyze the relationship of agricultural, industry and service industry, the

\footnotetext{
* Corresponding author: yuanyuandx@sina.com
} 
relationship between the sub-industries in service sector, in order to make an contribution to the transformation of Beijing economic development patterns.

\section{An analysis on the situation of Beijing service sector}

The statistics practices and existing research show that the service industry development is mainly manifested by the tertiary industry in Beijing. So the quantitative analysis and research on Beijing service sector are based on the third industry datum listed on the Beijing Statistical Yearbook and Beijing input-output tables. This paper follows previous practice.

\subsection{The overall observation on Beijing service sector}

The proportion of service industry in Beijing's GDP is close to the level of the developed countries, increased from $67.84 \%$ in 2004 to $76.07 \%$ in 2011 . The added value of Beijing services sector reaches 12363.18 in 2011 , increased 200.7 percent compare to 2004. The average annual growth rate reaches to the $28.7 \%$, which is higher than the annual GDP growth rate of $4.6 \%$ (See Chart 1 ).

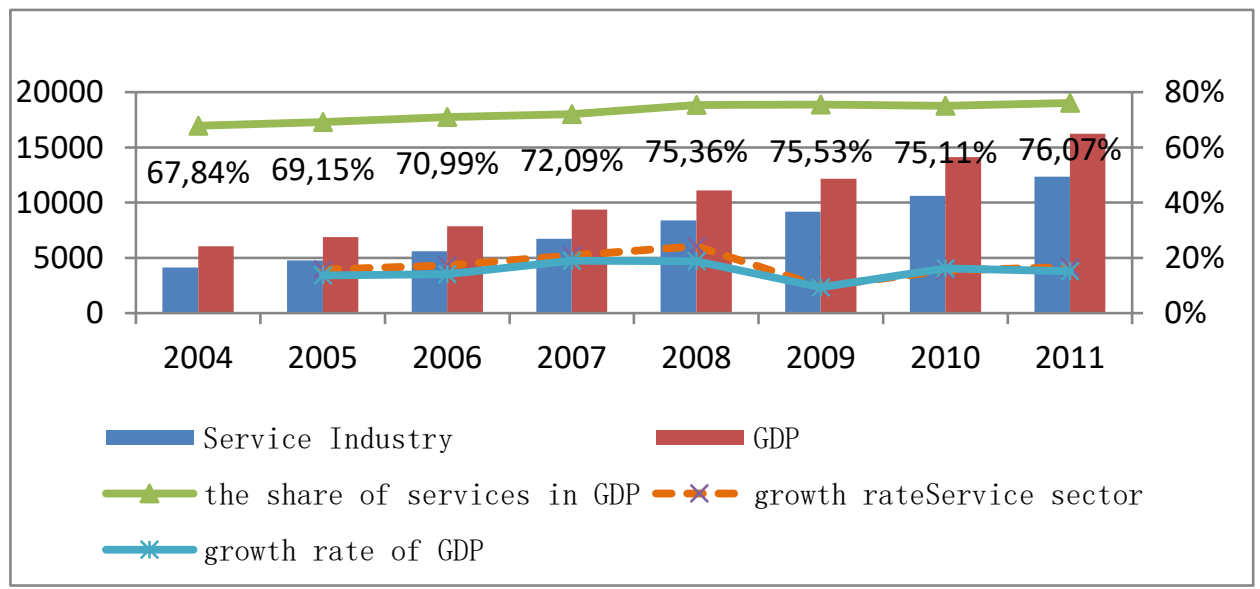

Chart 1. The relate indexes changes from 2004 to 2011 (unit: billion, \%)

Source: Author.

\subsection{The analysis of internal structure in Beijing service industry}

From 2005 to 2011, every sub-service industry in Beijing has shown good performances except for the two sub-industries, such as Residents service and other services. The rest 12 industries' average annual growth rate are more than two digits. Especially, the average annual growth rate of such industries named Leasing and business services, R\&D service and geological prospecting exceed $30 \%$, the other's average annual growth rate exceed $20 \%$ (See Chart 2). The contribution of each industry to added value of the whole service is different; the financial sector has a higher contribution in every year, but the growth rate of contribution is only $1.99 \%$ during the period; three sectors named Wholesale and Retail Trades, Leasing and business services, R\&D service and geological prospecting get $20 \%$ increase in the contribution, the sector of Health and social welfare and security makes an 3.24\% increase in the contribution to the added value of whole service. Apart from anything else, the remain nine industries' contribution to the added value of wholes service reduces differently. This shows that the advantage of Beijing service gradually reveal, the resources flow to the 
Comparative Advantage Industry. It was proved by statistical analysis: The variance of industries accounted for the proportion of whole service industry rose from 0.049 in 2005 to 0.056 in 2011.

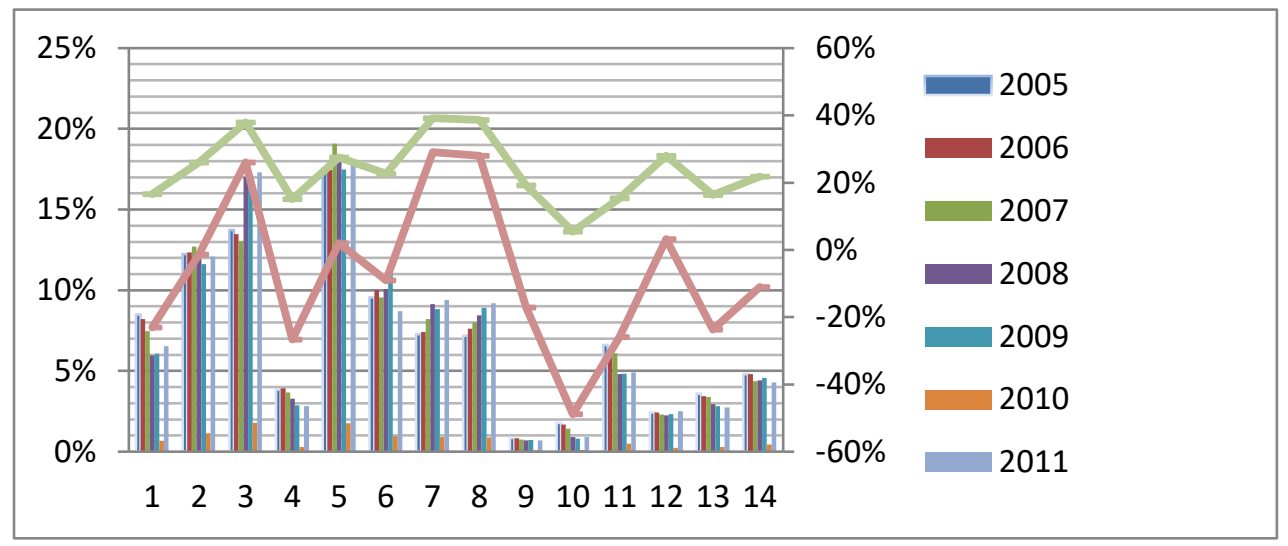

Chart 2. The share of each sector within service industry and the relates indexes from 2005 to 2011 Source: Author.

Note:1: Warehousing postal transportation; 2: Information transmission, computer services;3: Wholesale and Retail Trade; 4: Hotels and Catering Service; 5: Financial; 6: Real Estate; 7: Leasing and business services; 8: Scientific research and technology service of geological exploration; 9: Water conservancy environment public facility management; 10: Residents service and other services; 11: Education; 12: Social welfare and health protection; 13: Culture, sports and entertainment; 14: Public Management and Social Organization.

\section{The analysis of industrial interrelation in Beijing service}

\subsection{The analysis of correlation between industry and service industry}

According to the Beijing input-output tables, the complete consumption coefficient we counted show that the products from second industry are leading consumer goods for each sectors. The complete consumption coefficient decreased compared with 2007, but still higher than 2002's. At the same time, the three major industries' consumption from agricultures experienced a lowered after the first process, and the complete consumption coefficient has been a dramatic fall comparing with 2002 (see Table 1). While, the three major industries' consumption from service industry has increased significantly, especially in the agricultural recorded an impressive sales growth of $72 \%$.

The complete consumption coefficients and its change show that: with the development of Beijing's economy and its science and technology, the supportive role of agriculture in economic development is becoming smaller and smaller, but the dependence of agricultural to service industry is getting stronger. The main reason for this is that Beijing's agricultural policy concentration on sightseeing and leisure agriculture, the evidence we can get from Table 2. Although the second industry's contribution to the GDP of Beijing in reducing, but its supporting role in economic development is still very significant; the role of service in Beijing Economic development is growing, all departments' complete consumption coefficient to service sector grew by a large margin. 
Table 1. The complete consumption coefficient Beijing's industry in 2002, 2007 and 2010

\begin{tabular}{|l|c|c|c|c|c|c|c|c|c|c|c|c|c|}
\hline & \multicolumn{3}{|c}{ Agricultural } & $\begin{array}{c}\text { Growth } \\
\text { rate }\end{array}$ & \multicolumn{3}{c|}{ Manufacture } & $\begin{array}{c}\text { Growth } \\
\text { rate }\end{array}$ & \multicolumn{3}{|c|}{ Service } & $\begin{array}{c}\text { Growth } \\
\text { rate }\end{array}$ \\
\cline { 2 - 14 } & 2002 & 2007 & 2010 & & 2002 & 2007 & 2010 & & 2002 & 2007 & 2010 & \\
\hline Agricultural & 0.44 & 0.55 & 0.18 & -59 & 0.04 & 0.08 & 0.03 & -25 & 0.02 & 0.04 & 0.02 & 0 \\
\hline Manufacture & 0.86 & 0.98 & 0.84 & -2 & 1.65 & 2.14 & 1.97 & 19 & 0.71 & 1.07 & 1.06 & 49 \\
\hline Service & 0.40 & 0.44 & 0.69 & 72 & 0.66 & 0.58 & 1.08 & 64 & 0.67 & 0.62 & 1.06 & 58 \\
\hline
\end{tabular}

Source: Author.

The relationships of different services within industry with the first and second industry are different, the complete consumption coefficients agricultural to transportation. Warehousing, wholesale and retail, accommodation catering, scientific research are higher than 0.01 ; and there are great growth on the complete consumption coefficients of wholesale and retail, tourist industry. Scientific research as well as the public administration and social organization, all of the coefficients rise more than $500 \%$ (see table 2). The same situation happened in the second industry, some sectors' complete consumption coefficients are higher than 0.1 , such as transportation, finance, leasing, business service and comprehensive technical. Some sectors' complete consumption coefficients get a larger growth rate, which is higher than $300 \%$, especially in transportation, wholesale and retail, tourist industry as well as the public administration and social organization. But other sectors within service industry decreased in complete consumption coefficients comparing with 2002. The changes of service industry's consumption coefficients to the first and second industry show that the service industry had far less correlation to agricultural and the second industry. From 2002 to 2010 , the complete consumption coefficients to agricultural increased only appears in the leasing and commercial sector, tourism and comprehensive technical services, all other sector's coefficient reduced on different degrees; to the industry, the coefficient grew only appears in leasing and commercial sector and tourism.

Overall, the correlation between second industry and others is more stable, and the same index increases gradually in Beijing service industry to other industry. But, the correlation of service with two other industries is low and fluctuating, and concentrates on a few industries within service. 
Table 2. The change of each sectors complete consumption coefficient within services in 2002 and 2010

\begin{tabular}{|c|c|c|c|c|c|c|}
\hline & \multicolumn{2}{|c|}{ Agricultural } & \multirow{2}{*}{$\begin{array}{c}\text { Growth } \\
\text { rate } \\
(\%)\end{array}$} & \multicolumn{2}{|c|}{ Manufacture } & \multirow{2}{*}{$\begin{array}{c}\text { Growth } \\
\text { rate } \\
(\%)\end{array}$} \\
\hline & 2002 & 2010 & & 2002 & 2010 & \\
\hline Transportation and warehousing & 0.057 & 0.110 & 93 & 0.082 & 0.104 & 28 \\
\hline Post industry & 0.005 & 0.001 & -89 & 0.008 & 0.000 & -95 \\
\hline Information transmission computer services and software & 0.034 & 0.005 & -86 & 0.056 & 0.004 & -93 \\
\hline Wholesale and retail establishments & 0.016 & 0.122 & 661 & 0.026 & 0.125 & 371 \\
\hline Hotels and Catering Service & 0.017 & 0.013 & -25 & 0.027 & 0.011 & -60 \\
\hline Finance and Insurance & 0.073 & 0.016 & -79 & 0.104 & 0.023 & -78 \\
\hline Real estate & 0.021 & 0.003 & -86 & 0.035 & 0.003 & -90 \\
\hline Leasing and Business Service & 0.074 & 0.046 & -38 & 0.142 & 0.054 & -62 \\
\hline Tourism & 0.001 & 0.006 & 503 & 0.001 & 0.007 & 509 \\
\hline Scientific study & 0.011 & 0.075 & 583 & 0.029 & 0.030 & 4 \\
\hline Polytechnical Services & 0.064 & 0.026 & -59 & 0.104 & 0.002 & -98 \\
\hline Other Social Services & 0.004 & 0.002 & -44 & 0.010 & 0.003 & -71 \\
\hline Education & 0.003 & 0.003 & -2 & 0.004 & 0.002 & -53 \\
\hline Health, social security and social welfare & 0.004 & 0.000 & -98 & 0.005 & 0.000 & -99 \\
\hline Culture, sports and entertainment & 0.017 & 0.005 & -72 & 0.031 & 0.004 & -86 \\
\hline Public Management and Social Organization & 0.000 & 0.040 & 9795 & 0.001 & 0.008 & 923 \\
\hline
\end{tabular}

Source: Author.

\subsection{The analysis on driving force of service industry development of Beijing}

The indexes which reflect the inter-affects between different industries are the influence coefficient and response coefficient. The influence coefficient means that how many demands will be deduced in the whole national economy when one department produces an additional product; and the response coefficient represents that how much the department will be affected when each department produce an additional product. According to the Beijing input-output tables 2002 and 2010, we calculate the two indexes of three major industries in Beijing and listed in Table 3. The table show that both indexes of agricultural declined during the inspection period. This means that not only the function of pull on the economic development in the agricultural sector has been weakened, but the demand deduced from the development of Beijing economic for agriculture descent. The influence coefficient of industrial and response coefficient is the highest in the three industries. From 2002 to 2010, industrial influences coefficient gets a small growth, which increases 3.53 percent; but the response coefficient declined 1.67 percent. In 2002, the influence coefficient of service industry is the lowest in the three major industries, but there is a substantial increase; by 2010 , the index is second only to industry, and higher than $15.6 \%$ of agricultural. The absolute value of the response coefficient of service is the highest in the three industries, and gets a largest growth equal to $19.42 \%$.

There are sixteen sectors in the service industry, the influence coefficient of nine sectors has significantly increased, and 11 sectors' response coefficient has increased. There into, some sectors influence coefficient grow more than $15 \%$, such as wholesale and retail, leasing and business services. The sectors which increasing significantly on the response coefficient 
is including transportation shipping industry, wholesale and retail, leasing and business services, tourism, scientific research, education, and public administration and social organizations. Especially, some sectors response coefficient rose more than $49 \%$, such as scientific research, tourism, wholesale and retail and transportation shipping industry. So in general, Beijing's service industry gets an increasingly significant role in the economic development, especially in the pulling and driving force of the economic progress. In addition, no matter on the number of sectors or the grow rate, the response coefficients are higher than the influence coefficients. It suggests that the driving force to economy coming from service is stronger than the pulling force in Beijing, and the development of Beijing's service industry mainly depends on the expansion of demand.

Table 3. The influence coefficient and response coefficient and the changes of the all industries

\begin{tabular}{|c|c|c|c|c|c|c|}
\hline & \multicolumn{2}{|c|}{$\begin{array}{l}\text { Influence } \\
\text { coefficient }\end{array}$} & \multirow[t]{2}{*}{$\begin{array}{c}\text { Growth } \\
\text { rate } \%\end{array}$} & \multicolumn{2}{|c|}{$\begin{array}{l}\text { Response } \\
\text { coefficient }\end{array}$} & \multirow[t]{2}{*}{$\begin{array}{c}\text { Growth } \\
\text { rate } \%\end{array}$} \\
\hline & 2002 & 2010 & & 2002 & 2010 & \\
\hline Agricultural & 0.959 & 0.820 & -14.49 & 0.532 & 0.370 & -30.45 \\
\hline Manufacture & 1.190 & 1.232 & 3.53 & 1.499 & 1.474 & -1.67 \\
\hline Service & 0.851 & 0.948 & 11.40 & 0.968 & 1.156 & 19.42 \\
\hline Transportation and warehousing & 1.078 & 1.152 & 6.93 & 0.964 & 1.843 & 91.24 \\
\hline Post industry & 0.951 & 0.969 & 1.85 & 0.445 & 0.508 & 14.05 \\
\hline $\begin{array}{l}\text { Information transmission computer services and } \\
\text { software }\end{array}$ & 0.958 & 0.950 & -0.89 & 0.904 & 0.614 & -32.05 \\
\hline Wholesale and retail establishments & 0.818 & 0.996 & 21.84 & 0.541 & 1.345 & 148.64 \\
\hline Hotels and Catering Service & 1.060 & 1.004 & -5.30 & 0.656 & 0.738 & 12.41 \\
\hline Finance and Insurance & 0.876 & 0.915 & 4.42 & 1.294 & 0.808 & -37.53 \\
\hline Real estate & 0.987 & 0.887 & -10.09 & 0.838 & 0.584 & -30.33 \\
\hline Leasing and Business Service & 0.860 & 1.165 & 35.45 & 1.167 & 1.394 & 19.52 \\
\hline Tourism & 0.888 & 1.038 & 16.86 & 0.403 & 0.604 & 49.92 \\
\hline Scientific study & 1.000 & 1.083 & 8.34 & 0.576 & 0.859 & 49.19 \\
\hline Polytechnical Services & 1.048 & 0.974 & -7.08 & 0.750 & 0.527 & -29.70 \\
\hline Other Social Services & 0.978 & 0.934 & -4.44 & 0.468 & 0.544 & 16.26 \\
\hline Education & 0.955 & 0.871 & -8.82 & 0.441 & 0.580 & 31.68 \\
\hline Health, social security and social welfare & 1.160 & 0.942 & -18.82 & 0.447 & 0.494 & 10.44 \\
\hline Culture, sports and entertainment & 0.962 & 0.996 & 3.55 & 0.697 & 0.628 & -9.82 \\
\hline Public Management and Social Organization & 1.004 & 1.095 & 9.08 & 0.404 & 0.710 & 75.68 \\
\hline
\end{tabular}

Source: Author.

\section{Conclusion}

The foregoing research shows that the contribution of Beijing service industry to economic progress increased significantly, but the difference between the internal services industry has become increasingly apparent. At the same time, the correlation between the service industry and others is reinforced obviously, but it is limited to the a handful of sectors within service industry, for instance, transportation shipping industry, leasing and business services, tourism, polytechnic services. The other characteristic is that the development of Beijing's service industry mainly depends on the expansion of demand. In order to meet the goal of Beijing social and economic development, the service industry in Beijing should witness further development of the more sectors. 


\section{Improve the performance of producer service based on the industry development}

Industry is the foundation of economic development; it has been confirmed by the world economic development practice. It will cause the regional economy of industrial hollowing out if the development of industry is ignored. So, strengthen the basic role of industrial development will not only meet the inherent demands of economic development, but also the premise and foundation of service industry development. The sectors including transportation, warehouse and postal service, information transmission, computer services and software, wholesale and retail, finance, leasing and business services, technical services, scientific research and geological exploration are producer services, which provide intermediary services for the production process directly or indirectly. But if the second industry's development is not enough and lack of science and technology, the development of producer service industry is lack of necessary demand. Also, the development of producer services' efficient is a requirement of the optimization of industrial developing. But the calculation of the influence coefficient based on the input-output shows that the influence coefficient of producer service in Beijing is generally low. The index of sectors which includes the financial insurance, wholesale and retail get an weak growth, but is still less than 1. And worse still, there is an negative grow on the sectors of information transformation and polytechnical services during the period of 2002 to 2010.the situation of transportation and the scientific study which influence coefficient is higher than 1 slightly. This result may have negative impact to upgrade service industries in Beijing.

\section{Accelerate the construction of environment, create a good social environment for the development of service industry}

The key factor of the service industry's developing is the construction of talent team on service, because the talents have higher requirements on the environment for life. Although Beijing is the administrative capital of our country and its competitiveness are higher than other provinces on economic, science and technology and culture, but compares with the requirements of economic development, there is a big gap. Some sectors which provide service to the are lag behind in Beijing's services development, they are low on the correlation with the sectors within the service industry, agricultural and manufacture. Although the education's contribution to the development of Beijing Service is in the medium level in the 16 sectors (see chart 2), but it is in decline, and weak of correlation between agriculture and industry, and gradually decline. In addition, the influence coefficients of consumer service are also low, and reduced year by year.

The goal of Beijing services development is not the scale but to be a winner on the international competition, the accelerating of environment' construction is not the need to attract high talent team on services, but also the necessary to build the competitiveness system. For all these efforts, the factors of Porter's diamond model are perfect. Because the sectors above are not only the auxiliary and supporting factor to the industry development, but to cultivate the reasonable consumptive conceptions.

\section{References}

1. K. Wang, J. Wang, The strategy of undertaking the International service transfer in Beijing. Journal of Beijing Polytechnic University, 6, 15-21, (2006)

2. Q. Wu, Modern Servicing Industry in Beijing. Commercial Research, 19, 163-166, (2006)

3. J. Han, The empirical of Beijing services using FDI. International Economic Cooperation, 4, 57-59, (2008) 
4. L. Qiu, Industrial Relevancy and spatial distribution between producer services and manufacturing in Beijing city. Acta Geographical Sinica, 12, 96-106, (2008)

5. Ch. Hao, The statistical analysis economic level of Beijing. Journal of Anhui Agricultural Sciences, 17, 92-95, (2010)

6. X.-B. Wu, J. Chenjin, An analysis on structure and competitiveness of services industry in Beijing Based on dynamic shift - share method. Journal of International Trade, 3, 96-106, (2012) 